\title{
Dilemas de uma Nova Agenda de Desenvolvimento: um olhar sobre a Política Ambiental Brasileira
}

\section{Dilemmas of a New Development Agenda: a Look at the Brazilian Environmental Policy}

\author{
Diogo de Carvalho ANTUNES* \\ Bruna Ranção CONTI**
}

\begin{abstract}
RESUMO
O presente trabalho tem por objetivo discutir alguns dos novos desafios que se impõem ao Estado na promoção do desenvolvimento, com ênfase naqueles que dizem respeito à participação social na formulação e na implementação das políticas de meio ambiente brasileiras. A metodologia utilizada se baseou em revisão bibliográfica sobre os temas do papel do Estado no desenvolvimento e da participação social, relacionando-os com a gestão da política ambiental no Brasil, com foco nos conselhos de gestão por ela criados. Parte-se da constatação de que as tomadas de decisão a respeito das políticas de desenvolvimento não podem mais ficar concentradas nas mãos de técnicos especialistas, como aconteceu nas agendas de desenvolvimento do século XX (desenvolvimentismo e neoliberalismo). Tais agendas foram incapazes de resolver as crises econômicas, sociais e ambientais que hoje vivenciamos, o que traz para o primeiro plano a necessidade de uma nova agenda desenvolvimentista, baseada nos princípios da participação social e da ação do Estado na construção de projetos abrangentes e sustentáveis, articulando as múltiplas esferas entre o local e o global. Nesse sentido, a política ambiental brasileira é inovadora ao incorporar, em seus princípios, tanto a importância do papel do Estado na proteção dos bens comuns quanto a necessidade da criação de instâncias participativas. No entanto, não se pode perder de vista o fato de que as arenas de negociação social se inserem em esferas de poder simbólico, político e econômico, que muitas vezes podem privilegiar os interesses de grupos mais influentes.
\end{abstract}

Palavras-chave: desenvolvimento; participação social; política ambiental.

\begin{abstract}
This paper aims to discuss some of the new challenges faced by the State in promoting development, with emphasis on the challenges of social participation on the formulation and implementation of the Brazilian environmental policy. The methodology used is based on a review of the literature about the role

\footnotetext{
** Cientista Político (UFJF) e mestrando em Políticas Públicas, Estratégias e Desenvolvimento (PPED-UFRJ). Pesquisador do INCT-PPED/CNPq. E-mail: diogocantunes@gmail.com

"* Professora do Curso de Turismo da UFMG, doutoranda em Políticas Públicas, Estratégias e Desenvolvimento (PPED-UFRJ) e Pesquisadora do INCT-PPED/ CNPq. E-mail: bruna-conti@hotmail.com
} 
of the state in development and about social participation, linking these themes with the management of environmental policy in Brazil, and focusing on the management boards created by this policy. We start from the observation that decision-making about development policies can no longer be concentrated in the hands of technical experts, as it happened with the development agendas of the twentieth century (developmentalism and neoliberalism). Such agendas have been unable to solve the economic, social and environmental crises that we live today, what brings to the foreground the need of a new development agenda, based on the principles of social participation and action of the State in building comprehensive and sustainable projects, articulating the multiple levels from local to global. Following this movement, the Brazilian environmental policy innovates by incorporating on its principles both the important role of the state in protecting the commons, and the necessity of creating participatory bodies. However, we cannot lose sight of the fact that the negotiation arenas are embedded in social spheres of symbolic, political and economic power, which may often favor the interests of influential groups.

Keywords: development; social participation; environmental policy.

\section{Introdução}

As duas décadas finais do século XX foram marcadas por várias mudanças nas trajetórias políticas, econômicas e ideológicas, em níveis internacional e nacional. O início da década de 1980 traçou um momento crítico da História: no plano político, destacavam-se a crise do estado de bem-estar social (welfare state) nos países desenvolvidos ocidentais, a crise do regime militar no Brasil e a queda da União Soviética. No plano econômico, os reflexos das crises do petróleo eram sentidos mundialmente, assim como o aumento da inflação em vários países e o agravamento do problema da dívida externa no âmbito nacional. No plano ideológico, as ideias que defendiam a intervenção do Estado na economia e na sociedade, seja no Capitalismo ou no Socialismo, perdiam força junto com as crises.

Diante desse cenário, a agenda neoliberal emergiu, criticando e substituindo as agendas desenvolvimentistas que foram executadas dos anos 1930 aos anos 1970 nos países desenvolvidos e em alguns países em desenvolvimento. Essa agenda se baseou na defesa da democracia liberal, no campo político; nas reformas orientadas para o mercado e nas políticas de estabilização, no campo econômico; e no predomínio da teoria econômica ortodoxa, da globalização e do questionamento à intervenção estatal, no campo ideológico. Não é difícil notar a integração entre esses três campos e as mudanças que essa agenda implicou para as políticas de desenvolvimento nacionais, com destaque para a redução do papel do Estado na organização da vida econômica e social.

Segundo essa visão, os mercados, os atores econômicos (empresas, consumidores...) e a teoria econômica ortodoxa tomariam a dianteira e se encarregariam de promover o desenvolvimento. Caberia ao Estado somente se adaptar a tal contexto, implementando as melhores práticas sugeridas por esses atores, que se concentravam nas políticas pró-mercado e numa gestão pública tecnocrática.

A agenda neoliberal foi implementada nos países desenvolvidos e em desenvolvimento nos anos 1980 , 1990 e, com menos ímpeto, nos anos 2000. No entanto, as promessas de desenvolvimento econômico e social não se concretizaram para a maioria dos países que seguiram esse movimento. Além disso, essa agenda não levou em consideração as consequências negativas do capitalismo moderno para a base de recursos naturais do planeta, já que a disseminação da concepção de desenvolvimento como crescimento econômico e o aumento quantitativo do consumo propiciaram a superexploração dos recursos naturais, até então entendidos como abundantes, livres e gratuitos pela economia convencional. A ideia de uma crise ambiental passou a ser cada vez mais difundida, o que pode ser observado desde 1987, com a publicação do relatório da Comissão Mundial sobre Meio Ambiente e Desenvolvimento da ONU, intitulado Nosso Futuro Comum. Ademais, não bastasse a crise ambiental, o mundo vive agora outra crise política, econômica e ideológica.

O cenário que irá emergir dos desdobramentos dessas crises ainda é nebuloso, mas algumas direções podem ser apontadas. É amplamente constatado que a economia não pode mais ser separada ou privilegiada em detrimento dos outros aspectos do desenvolvimento, principalmente tendo em consideração o aspecto ambiental, já que a base de recursos naturais do planeta é finita. Da mesma forma, a ciência econômica não pode prescindir das outras ciências sociais na orientação das políticas de desenvolvimento. 
O contexto atual traz ainda a necessidade da volta do Estado como um ator relevante na formulação e na implementação de políticas de desenvolvimento, mas não é possível pensar esse movimento a partir da reedição dos projetos desenvolvimentistas do século XX, pois a relação entre Estado, sociedade, ambiente natural e mercado não é mais a mesma. A coalizão social e política que sustentava aqueles projetos envolvia uma classe média trabalhadora, industrial e homogênea; grandes conglomerados industriais nacionais; crescimento da urbanização; e um Estado capaz de exercer a coordenação, prover serviços públicos básicos (saúde, educação, infraestrutura e seguridade social), controlar os mercados e promover os interesses desenvolvimentistas (industrialização, exportações, tecnologia, crescimento econômico). Atualmente, a classe média não está necessariamente ligada à indústria e apresenta uma composição altamente heterodoxa, com objetivos dispersos. Os conglomerados nacionais deram lugar a empresas transnacionais, com interesses próprios e gestão fragmentada. A expansão desordenada das cidades torna-se cada vez mais insustentável. E o Estado vem perdendo a capacidade de coordenar os diversos interesses sociais e econômicos, prover a variedade de serviços públicos demandados pelas populações, estabelecer controles sobre os mercados e definir os objetivos do desenvolvimento (COHEN, 2000).

Ademais, entre os novos desafios às políticas de desenvolvimento, incluem-se: a instauração de uma relação mais harmônica entre sociedade e natureza, questão central para a concepção de desenvolvimento sustentável apresentada no relatório Brundtland (1987); um padrão de produção e consumo diferente do observado no capitalismo moderno (STIGLITZ, 2002); a ampliação tanto das oportunidades dos indivíduos nas áreas da economia, da política e da cultura quanto nos níveis de bem-estar das populações - desenvolvimento humano (PNUD, 1998); a expansão das liberdades substantivas dos cidadãos (SEN, 1999); o aprofundamento da democracia, por meio dos mecanismos deliberativos (COHEN, 2000); e a repartição mais equitativa dos ganhos econômicos proporcionados pela globalização e pela economia do conhecimento (DINIZ, 2010). Em virtude dessas mudanças, as novas políticas desenvolvimentistas devem cada vez mais priorizar ações em conjunto com a sociedade civil, pois precisam se basear em projetos abrangentes, com o esforço de definição de objetivos comuns, visão e acompanhamento de longo prazo (EVANS, 2008), proporcionando ainda que cada sociedade seja capaz de definir seu padrão de produção e consumo, a partir de sua experiência histórica e cultural (DIEGUES, 2001).
A observação dos desafios apresentados anteriormente permite considerar que, para a consolidação de uma nova lógica desenvolvimentista, é primordial que o desenvolvimento seja tratado a partir de uma abordagem transdisciplinar e complexa, englobando aspectos sociais, culturais, ambientais, políticos, econômicos, éticos, entre outros, além da participação social e política de todos os atores envolvidos nos projetos de desenvolvimento.

Apesar de a concretização dessa nova lógica ainda se encontrar em um estágio embrionário, algumas iniciativas demonstram, ainda que nas intenções, caminhar nesse sentido. A política ambiental brasileira, por exemplo, embora muitas vezes não consiga dialogar com os objetivos de desenvolvimento de outras áreas do Estado, se apresenta como uma política pioneira ao incorporar, em suas bases conceituais, alguns dos aspectos de uma nova lógica de desenvolvimento, principalmente no que diz respeito à necessidade da criação de instâncias participativas para a tomada de decisão e à importância do papel do Estado na proteção dos bens de interesse comum e na coordenação dos interesses sociais diversos. Essas características são ressaltadas por Carvalho (2005), quando este atribui à política ambiental brasileira uma "vocação democrática". Assim, a trajetória dessa política pode servir para o exame das potencialidades e dos limites da nova relação entre Estado e sociedade na implementação de políticas públicas, principalmente considerando as iniciativas de criação de espaços de participação social na gestão dos recursos naturais, com destaque para as consultas públicas e os conselhos consultivos e deliberativos.

Diante dessas constatações, o presente trabalho tem por objetivo discutir alguns dos novos desafios que se impõem ao Estado na promoção do desenvolvimento, com ênfase naqueles que dizem respeito à participação social na formulação e na implementação de políticas públicas. Para a avaliação da dinâmica desses desafios, será utilizado o exemplo dos conselhos de gestão definidos pelas políticas nacionais de meio ambiente do Brasil.

A metodologia utilizada se baseou em revisão bibliográfica sobre os temas do papel do Estado no desenvolvimento e da participação social, relacionando-os com a gestão da política ambiental no Brasil, com foco nos conselhos de gestão.

Para tanto, o trabalho está dividido em cinco seções, incluindo esta introdução. Na próxima seção é apresentada uma análise sobre as consequências gerais e locais da implementação da agenda neoliberal nos países. Tal análise 
estará concentrada no campo da economia pelo fato de que essa agenda se voltava estritamente ao aspecto econômico, derivando desse campo as medidas necessárias ao desenvolvimento. Dentro dessa lógica, a agenda neoliberal teve como um pressuposto básico a diminuição da intervenção do Estado no processo de desenvolvimento. É preciso então um breve mergulho na economia para mostrar como essa agenda falhou na promoção do desenvolvimento e no entendimento de sua complexidade. É a partir desse percurso histórico que será possível identificar as dificuldades para que o Estado volte a ter uma posição relevante no planejamento do desenvolvimento.

Levando-se em consideração tais dificuldades, na terceira seção são examinadas duas alternativas propostas para a viabilização de uma nova agenda desenvolvimentista na contemporaneidade: o "novo igualitarismo", de Joshua Cohen (2000), e o "Estado desenvolvimentista do século XXI", de Peter Evans (2008). Em seguida, o caso da política ambiental é utilizado como forma de verificação das possibilidades dessas alternativas, observando-se o papel dos conselhos de meio ambiente como meios de garantir a participação da sociedade civil na gestão de uma política pública, ao mesmo tempo em que preservam o papel do Estado como organizador dos interesses sociais.

Ao fim, uma breve conclusão procura unir os aspectos abordados no texto, destacando a importância de um pensamento complexo das políticas de desenvolvimento que integre as escalas intermediárias entre o local e o global.

\section{A agenda neoliberal, suas consequências e os princípios de uma nova agenda desenvolvimentista}

A agenda neoliberal emergiu na década de 1980 como resposta às crises econômicas e sociais iniciadas nos anos 1970. Baseada numa revisão do liberalismo econômico, essa agenda partia do pressuposto de que o projeto de organização da economia e da sociedade por intermédio do Estado havia falhado em promover o desenvolvimento no longo prazo. Tal visão tinha origem no diagnóstico de que a intervenção do Estado nos mercados, forte instrumento dos projetos desenvolvimentistas que prevaleceram nos países desenvolvidos e em desenvolvimento no pós-guerra, havia gerado grandes ineficiências econômicas, crises fiscais e um Estado com exagerado poder de determinação sobre a sociedade civil.

A solução desses problemas se daria então por uma mudança na direção das políticas de desenvolvimento, com a nova organização da sociedade sendo feita a partir dos mercados, numa escala global. Diante da redução das barreiras físicas e financeiras entre os países, do aumento do fluxo de produtos, serviços, capital e conhecimento, a eficiência dos mercados aumentaria, bastando que os governos promovessem a estrutura necessária ao livre funcionamento desses mercados para que o desenvolvimento se expandisse mundialmente, primeiro no aspecto econômico, depois nos outros aspectos. Essa solução implicava então em uma redução do poder político e econômico do Estado e em uma submissão dos problemas sociais e ambientais à lógica economicista.

Dentro do conjunto de recomendações da agenda neoliberal, destacavam-se: a liberalização do fluxo internacional comercial e de capitais; o equilíbrio dos orçamentos públicos, de preferência com superávit fiscal, promovido principalmente com a redução dos gastos públicos; a diminuição e a otimização da estrutura estatal, por meio das privatizações de setores que pudessem ficar nas mãos dos mercados e da utilização de técnicas de gestão avançadas para o aumento da produtividade das burocracias estatais; a flexibilização do mercado de trabalho; e a adoção de instituições modernas nos países em desenvolvimento ${ }^{1}$ (como a democracia liberal, o judiciário independente, o banco central autônomo e um sistema de propriedade intelectual forte).

Essa agenda foi aplicada tanto em países desenvolvidos quanto em países em desenvolvimento. Entre os primeiros, destacam-se Grã-Bretanha e Estados Unidos da América na aplicação das políticas recomendadas. Já os países em desenvolvimento a aplicar a agenda foram vários, com a orientação política das medidas combinada entre os governos nacionais e as organizações multilaterais (Banco Mundial e FMI), que exerceram grande influência através dos seus programas de estabilização econômica e desenvolvimento.

As consequências gerais que podem ser observadas da adoção da agenda neoliberal são várias, mas o balanço que

\footnotetext{
${ }^{1}$ É preciso destacar que a questão das instituições teve sua importância enfatizada pela agenda dos mercados em um segundo momento, após a aplicação das medidas anteriores.
} 
se faz dos seus resultados é predominantemente negativo (STIGLITZ, 2002). De fato, a globalização, acompanhada da diminuição das barreiras ao comércio, aos capitais e ao conhecimento, proporcionou a entrada de vários países na lógica econômica moderna, com a industrialização de suas economias e a proliferação das tecnologias avançadas. A inflação crescente nos anos 1970 e 1980, uma das principais justificativas para a implantação da agenda, foi controlada em boa parte dos países do mundo. Além disso, as multinacionais ganharam poder e aumentaram seus lucros consideravelmente, pois puderam aproveitar as economias proporcionadas pela abertura dos mercados e pela flexibilização das regulamentações nacionais.

Entretanto, a começar pelo argumento central dos defensores da agenda, o crescimento econômico nos países que aplicaram as recomendações foi, em geral, bem mais modesto do que o prometido. A desregulamentação dos mercados acabou promovendo a instabilidade econômica, através de crises provocadas pelos abusos de integrantes do mercado, pela especulação excessiva e pelas fugas de capitais repentinas dos países. A expressão maior desse movimento foi a crise financeira de 2008. Além dos problemas econômicos, também se constatou o aumento das desigualdades sociais nos países que seguiram as práticas recomendadas pela agenda (PALMA, 2011; STIGLITZ, 2002). Stiglitz também cita o agravamento das desigualdades entre países com a liberalização acelerada dos mercados nos países em desenvolvimento:

A liberalização do comércio deve supostamente otimizar a receita de um país, forçando os recursos a mover-se de usos menos produtivos para usos mais produtivos; como diriam os economistas, utilizando a vantagem comparativa. Entretanto, fazer com que os recursos com finalidades menos produtivas passem à produtividade zero não enriquece um país, e foi isso que, muitas vezes aconteceu [...] A ideologia do FMI afirmava que cargos novos e mais produtivos seriam criados à medida que funções antigas e ineficientes [...] fossem eliminadas. No entanto [...], é preciso ter capital e espírito empreendedor para gerar novas empresas e novos empregos, só que nos países em desenvolvimento faltam empregos pela falta de estudo, e faltam empresas pela falta de financiamentos bancários. (2002, p. 92, grifo do autor).
Foi também marcante nos últimos anos o agravamento dos problemas ambientais em nível mundial, dado que muitas vezes as iniciativas de proteção da natureza foram sobrepujadas pelos interesses econômicos (MEDEIROS; IRVING; GARAY, 2004).

No que toca à gestão das políticas públicas, as medidas de redução da estrutura do Estado e de melhoria da eficiência da burocracia tiveram, em geral, consequências como a concentração dos governos nas políticas econômicas em detrimento das políticas sociais (que foram direcionadas ao setor privado), a centralização das decisões políticas nas mãos do executivo e dos tecnocratas, a perda da importância da política como locus de orquestração dos interesses sociais para a promoção do bem comum e a marginalização das questões ambientais, tratadas muitas vezes como empecilho ao desenvolvimento (DINIZ, 2007, 2010; LETFWICH, 1995).

Por fim, as instituições defendidas pela agenda dos mercados não foram suficientes para promover o desenvolvimento. Os bancos centrais autônomos, por exemplo, passaram a tratar os objetivos de política monetária de uma maneira exclusivamente técnica, sem considerar os aspectos políticos e sociais envolvidos na questão. Quanto à adoção dos princípios da democracia liberal nos países, Leftwich (1995) enfatiza que, embora fosse uma conquista importante, a simples adoção desses princípios, distanciada da manutenção de políticas desenvolvimentistas e de um Estado com alta capacidade de mobilização de recursos e coalizão política, não levou ao desenvolvimento. Em outras palavras, o autor defende que o desenvolvimento é principalmente uma questão de organizar interesses sociais e fazer escolhas estratégicas. Sobre a democracia liberal, vale também retomar a análise de Diniz (2007), que afirma que a institucionalização das regras do jogo democrático não foi suficiente para superar três déficits históricos acumulados durante a constituição dos Estados na América Latina: o déficit de inclusão social, relacionado às desigualdades de renda, direitos e acesso à justiça presentes nas sociedades latino-americanas; o déficit da capacidade de implementação de políticas socialmente desejáveis por parte do Estado; e o déficit de accountability, dada a fraqueza dos mecanismos de responsabilização pública dos governantes perante a sociedade e outras instâncias de poder. A autora vê a necessidade de "recuperar a importância da dimensão social da democracia e ampliar os direitos de cidadania, sobretudo quanto aos direitos civis e sociais, reduzindo substancialmente a distância entre democracia formal e substantiva" (DINIZ, 2007, p. 24). 
A observação das consequências da implementação da agenda neoliberal permite que sejam feitas algumas conclusões. Pode-se afirmar que dois problemas principais estão presentes em todas as consequências expostas. Um deles é o tratamento da questão do desenvolvimento como algo meramente econômico, perdendo-se de vista os aspectos sociais, políticos e ambientais nele presentes. As ações econômicas recomendadas tiveram efeitos sociais claros, como o desemprego, a desigualdade e a superexploração da base de recursos naturais, que são tão ou mais relevantes que a produtividade da economia. Além disso, é fundamental o efeito que as diferenças de trajetórias históricas, cultura e contexto socioeconômico dos países possuem para o desenvolvimento, algo que foi desconsiderado pela agenda neoliberal quando esta recomendou ações uniformes, na perspectiva de que a globalização minimizaria as diferenças nacionais. Ademais, é preciso considerar que as ações econômicas se inserem num contexto político, de relações de poder e articulação de interesses nos campos nacionais e internacionais. Nesse sentido, a tomada de decisões a respeito das políticas de desenvolvimento não pode ficar concentrada nas mãos de técnicos especialistas.

$\mathrm{O}$ segundo problema diz respeito à visão simplista de que o Estado era a causa das crises ocorridas nos anos 1970/1980, visão que originou a ideia de que o Estado deveria reduzir o seu papel no planejamento do desenvolvimento, deixando a organização do mercado e da sociedade submetidos à espontaneidade. A história mostrou que a autorregulação dos mercados foi incapaz de prever comportamentos abusivos dos seus participantes e promover a coordenação de atividades necessária ao desenvolvimento, mesmo que se atente somente ao campo econômico (FIANI, 2011). Da mesma forma, a organização espontânea da sociedade civil, expressa por meio das ONGs, por exemplo, não foi suficiente para resolver as diversas questões sociais e ambientais envolvidas no processo de desenvolvimento.

Ignorar a existência desses dois problemas nos processos de implementação da agenda neoliberal foi um erro desastroso para os países que a colocaram em prática. Assim, nos últimos anos constatou-se a necessidade de uma nova agenda que considere o desenvolvimento para além do crescimento econômico e a retomada do Estado na coordenação dos projetos desenvolvimentistas. No entanto, essa nova agenda precisa também levar em conta a evolução das sociedades e as limitações dos antigos projetos desenvolvimentistas, ou seja, deve se ater a princípios como o aprofundamento da democracia - com a participação da sociedade na definição e execução das políticas públicas -, a expansão das liberdades dos cidadãos, a redução das desigualdades e a garantia de manutenção dos recursos naturais (DINIZ, 2010). Isso se faz necessário para que os objetivos a serem perseguidos pelas políticas públicas sejam definidos e sustentados por uma coalizão ampla de interesses sociais (EVANS, 2008). É também necessário lidar com a questão da globalização, que deve ser uma oportunidade, e não uma restrição, para a capacidade de ação dos Estados (DINIZ, 2007). Por último, mas não menos importante, destaca-se ainda a crise ambiental, evidenciada a partir dos anos 1990, que trouxe para o primeiro plano a necessidade de que o novo padrão de desenvolvimento seja focado na sustentabilidade e na integração entre sociedade e natureza (DIEGUES, 1996).

Diante do apresentado, o cenário atual torna possível e necessária a consolidação de uma nova agenda desenvolvimentista. Não são poucas as propostas para essa nova agenda. Para citar algumas, destacam-se as propostas do ecodesenvolvimento (SACHS, 1980), do desenvolvimento sustentável (CMMAD, 1991), do desenvolvimento como liberdade (SEN, 2000), dentre outros. ${ }^{2}$ No entanto, embora haja uma abundância de contribuições sobre os princípios que devem sustentar essa nova lógica, a sua implementação ainda é algo menos discutido. Nesse sentido, busca-se aqui apresentar uma pequena contribuição à análise dos desafios da implementação da nova lógica desenvolvimentista, partindo da discussão da ciência política sobre as mudanças necessárias para o estabelecimento de mecanismos de participação social e de uma nova atitude do Estado na condução das políticas públicas para o século XXI. Para tanto, serão utilizados os trabalhos de Joshua Cohen (2000) e Peter Evans (2008). A principal contribuição de Cohen diz respeito à descentralização do poder de regulação e resolução de problemas locais, movimento que se daria do Estado em direção às arenas deliberativas locais. Evans, por sua vez, vai além da descentralização ao discutir como o Estado pode atuar na expansão das capacidades humanas, tornando possível que os cidadãos consigam definir e alcançar os seus próprios objetivos de bem-estar.

Essas contribuições serão utilizadas posteriormente para pensar as potencialidades e limites dos conselhos de gestão da política ambiental brasileira, uma tentativa do

${ }^{2}$ Para uma revisão sobre as novas concepções de desenvolvimento, tendo em vista o contexto do desenvolvimento sustentável, consultar Calegare e Silva Júnior (2011). 
poder público de conciliar a descentralização das tomadas de decisões relativas a algumas questões ambientais e a capacidade dos stakeholders em conjugar seus diversos interesses em prol da proteção da natureza, através da mediação do Estado.

\section{Desenvolvimento e democracia: sustentabilidade no século XXI}

Embora Joshua Cohen não trate diretamente do tema desenvolvimento em sua reflexão, ele defende a ideia de que para a construção de sociedades mais igualitárias no mundo globalizado do século XXI é necessária uma "esfera pública com maior envolvimento direto dos cidadãos na solução de problemas coletivos, o que aponta para a construção de uma democracia mais direta e mais deliberativa" (2000, p. 162). O autor se refere, inclusive, a experimentos de democracia direta deliberativa que vêm acontecendo nos Estados Unidos da América, no tema da regulação ambiental, entre outros. Nesse novo modelo de gestão das políticas públicas, seria necessária uma base social forte, com organizações e arenas capazes de garantir a representação de interesses que não seriam necessariamente representados de uma maneira espontânea. Esse programa foi chamado por Cohen de "novo igualitarismo", uma filosofia de governo que prevê a resolução de problemas através de arenas deliberativas, conjuntos de cidadãos que estão mais próximos e mais inteirados dos problemas a serem resolvidos do que a burocracia estatal. Para que essas alternativas de solução de problemas se formem, seria necessário o envolvimento direto de cidadãos na resolução de assuntos coletivos, o que seria possibilitado somente com a descentralização de responsabilidades até então localizadas nas mãos do Estado.

É nessa descentralização que se situa o ponto principal da proposta de Cohen. O autor identifica dois problemas centrais que se impõem atualmente para o Estado: o primeiro é que ele vem sendo chamado a regular um campo bem maior e mais complexo de atividades do que no passado (período anterior aos anos 1970, quando predominou a velha agenda desenvolvimentista), tendo chegado ao seu limite, dado que suas agências frequentemente não possuem o conhecimento específico necessário à regulação dessas atividades; o segundo problema é que a classe trabalhadora baseada na produção em massa, ponto de sustentação do projeto desenvolvimentista do século $\mathrm{XX}$, tem dado lugar a uma composição bem mais heterogênea de indivíduos na sociedade atual, devido ao grande aumento da divisão de trabalho na contemporaneidade. A solução para esses problemas estaria então na distribuição do poder de regulação e resolução de problemas locais às arenas deliberativas locais. Essas arenas teriam uma melhor capacidade de obter informações específicas, monitorar os contextos locais e promover a cooperação, devido à sua inserção local e ao seu escopo limitado. Elas não seriam necessariamente as associações tradicionais (ex: sindicatos e partidos), seriam associações criadas para o tratamento de preocupações comuns numa comunidade, recebendo para isso poder e recursos do Estado, sem estarem, entretanto, filiadas a este.

$\mathrm{O}$ autor cita duas dificuldades relacionadas a essa nova estrutura. Uma delas seria a "armadilha do localismo", ou seja, o risco de que a estrutura de arenas deliberativas locais faça com que a política perca o seu caráter universalista, já que essas arenas tratariam de problemas localizados. Para a resolução dessa dificuldade, Cohen propõe que sejam construídas redes, onde as associações comparem as soluções estabelecidas para problemas similares em outras localidades. Além disso, esclarece que o apoio estatal a essas associações estaria condicionado à resolução, por parte destas, de questões de interesse público, como a pobreza ou a proteção dos recursos naturais. Outra dificuldade relevante, é que:

O tipo certo de organizações e arenas não emerge natural ou espontaneamente, nem para os propósitos de garantir uma igualdade política relativamente justa, nem para a solução de problemas requerida em uma ordem igualitária bem-sucedida. Tampouco podemos observar alguma tendência evidente para o seu desenvolvimento autônomo diante da atual diversidade de aspirações políticas. (COHEN, 2000, p. 164).

Sendo assim, o novo igualitarismo precisa de uma base social forte e de poderes públicos que forjem ideais igualitários e democráticos através da transferência de responsabilidade da solução de problemas locais às associações locais. A partir do momento em que essas associações estivessem operando, seu próprio funcionamento promoveria ideais igualitários e democráticos, formando um ciclo virtuoso.

Essa visão se insere no programa da democracia deliberativa, que propõe o aprofundamento da democracia para além dos aspectos representativos. Pensando a questão do desenvolvimento, pode-se afirmar que, segundo essa 
corrente, a deliberação pública seria o instrumento fundamental para tornar a definição dos objetivos e a execução das políticas públicas efetivamente orientados para o aumento do bem-estar geral.

Como se pode notar, o novo igualitarismo vai muito além de um tratamento técnico e economicista da política, da democracia e do desenvolvimento, mas não deixa de incluir a questão econômica. Sua aposta para o aumento da produtividade das economias está relacionada ao aumento das capacidades dos indivíduos, à equalização das oportunidades e à resolução dos problemas sociais - inclusive ambientais - que o Estado e as empresas não dão conta de tratar.

Uma crítica que pode ser feita a essa visão se baseia no fato de que ela dá pouca atenção à possibilidade de reprodução, nas arenas deliberativas locais, das diferenças de poder existentes nas sociedades contemporâneas, em níveis local, regional, nacional e global. No limite, as arenas deliberativas podem se tornar inclusive instrumentos de legitimação da desigualdade de poder entre os setores sociais, dado que as elites possuem maior capacidade de mobilização e maiores recursos. Tais dificuldades poderão ser vistas na prática, na seção do presente artigo em que se discute os conselhos de gestão da política ambiental como arenas deliberativas locais.

Considerando o aprofundamento da democracia e a questão da globalização, tratados por Cohen, mas ao mesmo tempo enfatizando o papel do Estado na promoção do desenvolvimento, está o trabalho de Peter Evans (2008). Partindo da análise de três correntes da teoria moderna do desenvolvimento (New Growth, Abordagem Institucionalista e Abordagem das Capacidades), o autor chega a um ponto comum que deve iluminar a atuação do Estado desenvolvimentista do século XXI. Esse ponto se caracteriza na busca da expansão das capacidades humanas, com o Estado proporcionando aos cidadãos acesso amplo ao estoque de ideias disponíveis a uma sociedade, incentivando a efetiva utilização desse estoque e a geração de novas ideias adaptadas às circunstâncias dessa sociedade.

Para chegar a esse ponto comum, Evans busca na teoria do New Growth a ideia de que as novas políticas de desenvolvimento devem se atentar para a exploração da economia do conhecimento. Da abordagem institucionalista, o autor busca a ideia de que a promoção do desenvolvimento depende de construções e reconstruções institucionais, ou seja, regras do jogo que influenciam as atitudes dos atores sociais na direção de atividades de maior retorno econômico e social. Por fim, a abordagem das capacidades - da qual o principal autor é Amartya Sen - fornece a ideia de que somente através da interação pública e da deliberação ampla para a resolução dos problemas que acometem uma sociedade é possível definir metas de desenvolvimento e meios para atingi-las.

Ao explorar as relações entre essas três teorias, Evans conclui que, para uma estratégia de desenvolvimento baseada na expansão das capacidades humanas, é fundamental o engajamento dos atores sociais na implementação das políticas, dado que a capacidade de fazer escolhas que afetam o bem-estar futuro é uma das mais importantes para o desenvolvimento. Além disso, o estabelecimento de canais entre Estado e sociedade é essencial para que o Estado obtenha informações sobre onde os recursos devem ser melhor alocados.

Ao discutir as políticas desenvolvimentistas do século XX, Evans já enfatizava a necessidade de combinação de características de autonomia da burocracia estatal - para a manutenção de um corpo político organizado, com capacidade de intervenção na economia e na sociedade - e de enraizamento, nos grupos sociais, das perspectivas que orientam as políticas desenvolvimentistas - para que o corpo burocrático não se isolasse em um projeto político próprio, desconsiderando os anseios da sociedade. Para a política de desenvolvimento do século XXI, baseada na expansão das capacidades humanas, na sustentabilidade e na exploração da economia do conhecimento, o autor vê como imprescindível uma ligação mais estreita entre o Estado e a sociedade civil na definição das necessidades socialmente relevantes para o desenvolvimento e na ampliação das informações estratégicas disponíveis para a formulação de políticas. Enquanto o enraizamento no século XX se caracterizou por uma parceria entre o Estado e as elites capitalistas nacionais, atualmente essa ligação deveria ser expandida para a sociedade civil como um todo, tarefa muito mais difícil que a anterior, mas que seria possibilitada pela via dos mecanismos de democracia deliberativa: poder aos cidadãos na formulação e na execução das políticas públicas.

Nesse sentido, Evans se aproxima da tentativa de Cohen de enfrentar o problema da complexidade crescente da sociedade e da economia atual, mas dá ao Estado um papel central nesse enfrentamento - na função de organizador e executor do interesse coletivo.

Tendo em vista as contribuições de Cohen e Evans para a implementação de uma nova lógica de desenvolvimento - baseada nos princípios da equidade, da participação social, da sustentabilidade e do Estado como promotor dos 
interesses coletivos -, pode-se perceber que as políticas ambientais estão fortemente integradas nesse processo.

Nesse sentido, é interessante observar a experiência da política ambiental brasileira, que vem incorporando, desde sua regulamentação, mecanismos de gestão que buscam articular os interesses do Estado, do mercado e da sociedade civil, tais como os conselhos consultivos e deliberativos e as consultas públicas. Esses mecanismos podem ser tidos como exemplos de aplicação prática dos princípios da democracia deliberativa na formulação e na implementação das políticas públicas. ${ }^{3}$ Sendo assim, o estudo da dinâmica de tais mecanismos na política ambiental brasileira - com foco nos conselhos - se mostra uma oportunidade para a reflexão sobre as alternativas propostas por Cohen e Evans.

\section{A política ambiental brasileira como locus de verificação das propostas da nova agenda desenvolvimentista}

Desde a década de 1970, quando se instaurou nos fóruns ambientalistas globais a discussão sobre desenvolvimento sustentável, as políticas ambientais tomaram um rumo alternativo às agendas desenvolvimentistas e neoliberais no que tange aos objetivos e caminhos possíveis ao desenvolvimento, já que essas agendas davam pouco espaço aos aspectos da sustentabilidade ambiental e da justiça social, centrais para a concepção de desenvolvimento sustentável. No contexto nacional, o Brasil vivia um momento de efervescência da cidadania, marcado pelo enfraquecimento da ditadura militar e pelo fortalecimento dos movimentos sociais e de redemocratização do país. Além disso, a sociedade brasileira se dava conta do grande passivo ambiental causado pelas "políticas de desenvolvimento exclusivamente voltadas para o crescimento econômico", levadas adiante por um Estado "marcado por uma concepção intervencionista, corporativa e patrimonialista, que ainda persiste em alguns casos [...] inibindo a organização da sociedade civil" (CARVALHO, 2005, p. 260).

É essa percepção que influencia a criação da Política Nacional do Meio Ambiente (Lei $n^{0}$ 6.938/81), desenvolvida num contexto de esforço extraordinário de setores da sociedade civil brasileira para "mudar o papel do Estado" e garantir "o fim da inércia do Poder Executivo em relação à degradação ambiental do País" (CARVALHO, 2005, p. 261).
Como resultado, essa política representou um primeiro passo no estabelecimento de um modelo de gestão alternativo, tanto ao estilo de gestão autoritário e tecnocrático do Estado no período militar (que caracterizava o contexto nacional) quanto ao estilo minimalista e gerencial da agenda neoliberal (que tinha crescente influência no contexto internacional). Esse novo modelo previa que o processo decisório referente à gestão ambiental deixaria de se basear em decisões unilaterais da autoridade pública para estabelecer canais de negociação e decisão junto à sociedade civil (CARVALHO, 2005) - apesar das inúmeras limitações ainda existentes. Para Paehlke e Torgerson (2005), isso se deu no momento em que as abordagens administrativas da política ambiental passaram a não ser mais suficientes, por não incorporar os conhecimentos locais às tomadas de decisão, e em função da complexidade que envolve as questões ambientais.

Um dos mecanismos criados pela Lei 6.938/81, para a gestão compartilhada dos recursos naturais, foi o Conselho Nacional do Meio Ambiente (CONAMA), colegiado de natureza deliberativa e consultiva que assegurava a participação, na formulação e na implementação da Política Nacional do Meio Ambiente, de representantes dos seguintes setores: órgãos federais, estaduais e municipais, setor empresarial e sociedade civil. Esse foi o primeiro conselho federal de caráter deliberativo com participação social no Brasil. Ao longo dos anos de sua existência, o CONAMA passou por algumas mudanças, geralmente no sentido de ampliar a participação social, sendo a mais significativa a reforma entre 1999 e 2001. O colegiado, que antes era composto por 72 conselheiros, passou a contar com mais de 100 conselheiros, ampliando a participação dos municípios, da sociedade civil e do setor empresarial. Além disso, foram criados os grupos de trabalho, abrindo a elaboração das resoluções à participação de toda a sociedade - já que antes as decisões eram tomadas somente pelos conselheiros que participavam de câmaras técnicas (CONAMA, 2008).

O Sistema Nacional do Meio Ambiente (SISNAMA), estabelecido pela mesma lei que criou o CONAMA, determinava a descentralização da gestão das políticas para os níveis estaduais e municipais, prevendo a criação de órgãos executivos para cada uma dessas instâncias. Caberia a esses órgãos a execução de programas, projetos, o controle e a fiscalização de atividades capazes de provocar a degradação ambiental. É a partir da criação dessa lei, por exemplo, que os conselhos estaduais passaram a adquirir um maior

\footnotetext{
${ }^{3}$ Embora esses mecanismos não sejam resultado de uma aplicação direta das ideias dos dois autores, eles refletem um esforço que se aproxima da nova concepção de desenvolvimento contemplada por essas ideias.
} 
protagonismo na gestão ambiental, tornando-se um modelo institucionalizado de gestão. Como afirma Ribeiro (2003, p. 10), "a criação do Conselho Nacional de Meio Ambiente - CONAMA - em 1981 fortaleceu e passou a influenciar a ideia [dos conselhos] em todo o território nacional". Atualmente, todos os Estados brasileiros, além do Distrito Federal, contam com um conselho estadual de meio ambiente.

Segundo Ribeiro (2003), a capacidade de mobilização social que esses conselhos estaduais conseguem alcançar no Brasil deve-se ao fato de que o caráter deliberativo dessas instâncias proporciona aos seus conselheiros real poder de decisão e interferência sobre as questões ambientais no seu território, por exemplo, na concessão de licenças e aplicação de penalidades. O autor afirma ainda que "ter participado da elaboração ou, pelo menos, da aprovação de uma norma gera a responsabilidade do compromisso de sua fiel observância" (2003, p. 12). Nesse sentido, resgata-se o argumento de Cohen, para o qual a deliberação pública, num contexto de descentralização de responsabilidades antes localizadas somente nas mãos do Estado, seria o instrumento fundamental para incentivar o engajamento público e a construção de arenas deliberativas locais ativas na formulação de objetivos e na implementação das políticas públicas. Diante dessa constatação, pode-se questionar a capacidade dos conselhos consultivos - presentes em outras instâncias da política ambiental, como nas Unidades de Conservação de Proteção Integral - em promover o engajamento dos atores locais na solução dos problemas públicos, já que o elemento motivador descrito por Ribeiro e presente no argumento de Cohen - a deliberação - não está contemplado nessa modalidade de gestão.

Apesar do caráter pioneiro dos conselhos de gestão do meio ambiente no que concerne à participação pública na formulação e na implementação de políticas - prática defendida tanto por Cohen, quanto por Evans -, algumas limitações são também identificadas. Feldman (2002) ressalta que muitos governos apresentam dificuldade em compreender a lentidão dos processos de participação e negociação social. Como a tomada de decisão tende a ser uma tarefa difícil em processos de deliberação pública, já que estes envolvem diversos atores e interesses, a eficiência dos conselhos pode ser questionada em função da urgência de algumas questões. É preciso então encontrar um equilíbrio entre rapidez na resolução de determinadas questões e representatividade das decisões tomadas.

Ademais, há que se atentar para o fato de que muitas vezes os mecanismos participativos são estabelecidos somente para cumprir o que é determinado pela legislação, sem apresentar resultados efetivos ou servindo somente para legitimar decisões previamente tomadas pelos gestores públicos. Evans (2008) também ressalta essa dificuldade, ao afirmar que a habilidade exigida das burocracias para o estabelecimento de laços fortes entre Estado e sociedade civil é muito mais política do que técnica, ou seja, os gestores públicos precisam entender a formulação das políticas públicas como uma tarefa que deve ser realizada em diálogo constante com a população a que essas políticas se dirigem.

Outro desafio a ser enfrentado diz respeito à representatividade dos atores sociais presentes nos conselhos e à legitimidade dos grupos que ocupam as cadeiras dessas instâncias de negociação. Ribeiro (2003) enfatiza a importância de haver um equilíbrio entre os vários grupos de interesse existentes, tanto entre as representações governamentais e da sociedade civil como no interior dessas duas esferas de representação - para que não se construam oligopólios nessas esferas. Complementarmente, é preciso aprimorar os mecanismos de transparência e controle social das ações dos representantes.

Por fim, Feldman (2002) salienta a necessidade de um maior aporte de recursos financeiros para estimular a participação de todos os atores sociais e melhor aparelhar os conselhos, por exemplo, através da contratação de estudos técnicos para subsidiar a tomada de decisão.

No âmbito da criação e gestão de áreas protegidas - uma das principais estratégias nacionais de proteção da natureza -, a legislação ambiental brasileira também tem buscado incorporar progressivamente o compromisso da participação social, aproximando-se dos princípios da democracia deliberativa. Esse compromisso se materializa no Sistema Nacional de Unidades de Conservação (SNUC), que avança no sentido de assegurar os mecanismos e procedimentos necessários à participação efetiva das populações locais na criação, implantação e gestão das Unidades de Conservação. ${ }^{4}$ Dentre esses mecanismos, destacam-se os conselhos de gestão ${ }^{5}$ das Unidades de Conservação (UCs).

\footnotetext{
${ }^{4}$ Espaço territorial e seus recursos ambientais, incluindo as águas jurisdicionais, com características naturais relevantes, legalmente instituído pelo Poder Público, com objetivos de conservação e limites definidos, sob regime especial de administração, ao qual se aplicam garantias adequadas de proteção (BRASIL, 2000). Essa nova terminologia foi utilizada para designar o conjunto de áreas protegidas que seriam contempladas pelo Sistema.

${ }^{5} \mathrm{O}$ Conselho é uma instância constituída por entidades representativas dos diversos segmentos da sociedade relacionados a uma unidade de conservação, podendo ser de caráter consultivo ou deliberativo (BRASIL, 2000).
} 
Para Gohn (apud IRVING et al., 2006), esses conselhos, em tese, representam instrumentos de participação social capazes de articular os representantes da sociedade civil e do poder público em ações relativas à gestão de áreas de proteção ambiental, sendo, portanto, arenas potenciais para a negociação de conflitos - o que se aproxima da ideia de arenas deliberativas locais de Cohen.

No entanto, apesar do avanço do arcabouço legal brasileiro para essa questão, a sua aplicação acontece ainda de maneira gradual. Irving (2010) argumenta que, se por um lado a participação da sociedade na gestão de UCs foi contemplada nesse arcabouço legal, por outro os mecanismos participativos de governança estão ainda sendo testados e aperfeiçoados.

Em primeiro lugar, é importante ter em mente o real alcance dos conselhos, visto que eles se inserem em campos de forças, sendo diretamente influenciados pela dinâmica sociocultural e política da região de inserção de cada UC (IRVING; MATOS, 2006). Brandão (2007) também destaca que a valorização das arenas locais não pode perder de vista os conflitos políticos e a estruturação das classes sociais presentes em uma sociedade. Dessa forma, é possível que os conselhos tenham pouca efetividade em equilibrar os interesses entre os grupos representados ou de fazer valer as decisões adotadas em favor daqueles de menor poder político, econômico e ideológico.

Diante desse cenário, fica evidente o papel do Estado em promover oportunidades equânimes de participação dentro das arenas deliberativas e atuar de maneira efetivamente coordenada, levando sempre em consideração as decisões tomadas em conjunto. Nesse aspecto, o argumento de Evans se faz relevante. Como o autor discute, ao Estado do século XXI não cabe somente a tarefa de descentralizar o poder; é também preciso que ele tenha um papel ativo na gestão dos mecanismos participativos, promovendo a equidade para garantir que as diferenças de capital econômico e social dos diversos atores envolvidos nesses espaços não os tornem meras esferas de reprodução das diferenças de poder existentes em uma sociedade. Sem que se atente a essas questões, a expansão das capacidades humanas proporcionada pelos mecanismos deliberativos fica prejudicada.

Além disso, a democratização e a descentralização das tomadas de decisão, fundamentais para o empoderamento dos conselhos, devem vir acompanhadas de uma preocupação por parte do Estado em evitar que essas decisões gerem externalidades negativas e que haja uma perda do caráter universalista das políticas, não só no sentido do que Cohen (2000) chamou de "armadilha do localismo", mas também levando em consideração os macroprocessos e as macrodecisões, inseridos nas "múltiplas escalas entre o local e o global" (BRANDÃO, 2007). Azevedo e Scardua (2006), tratando da experiência da descentralização do licenciamento ambiental em Mato Grosso, mostram como o poder econômico pode "privatizar" a esfera pública e flexibilizar a regulamentação quando a gestão da política ambiental é delegada às esferas locais sem que haja um acompanhamento do governo federal no sentido de equilibrar os conflitos de interesse ambientais.

Diante da reflexão sobre o papel dos conselhos na política ambiental brasileira, fica evidente a necessidade de se considerar tanto a participação efetiva da sociedade civil na construção das políticas quanto a manutenção do poder do Estado em promover a cooperação e garantir a integração entre as esferas local, regional e nacional. Apesar de os documentos da política ambiental brasileira incorporarem esses pressupostos, ainda há uma longa caminhada para que a estrutura institucional construída se enraíze na sociedade e na burocracia estatal.

Ademais, o esforço de construção de uma nova estrutura institucional de gestão das políticas públicas não pode ser exclusivo da área ambiental, mas deve ser integrado às outras áreas de desenvolvimento, refletindo uma visão sistêmica das políticas públicas. Caso contrário, corre-se o risco de que se estabeleçam conflitos entre os objetivos e as práticas das diversas frentes do desenvolvimento, minimizando os efeitos das políticas que procuram promover uma nova lógica de aumento do bem-estar e atuando em prol das velhas práticas que dão maior atenção ao aspecto do crescimento econômico. Esse é um problema que vem sendo enfrentado pela política ambiental, tanto no Brasil quanto em outros países, uma vez que interesses econômicos acabam sobrepujando as tentativas de incorporação de práticas sustentáveis às políticas públicas.

\section{Conclusão}

As crises políticas, econômicas e ideológicas dos anos 1970/1980 marcaram a desestruturação das políticas desenvolvimentistas vigentes até então e possibilitaram a consolidação da agenda neoliberal no direcionamento das políticas de desenvolvimento de diversos países. Passadas algumas décadas desde o estabelecimento dessa agenda, os resultados alcançados não foram suficientes para justificar a 
manutenção dessa concepção de desenvolvimento. Houve, inclusive, um agravamento de problemas sociais, ambientais e econômicos, em vários aspectos. Presenciam-se atualmente novas crises políticas (como constatado nas manifestações populares na Europa e no mundo árabe), econômicas (como a crise financeira de 2008 e a crise atual da dívida dos países europeus) e ideológicas (como a própria queda do ideário neoliberal), além da crise ambiental, que se tornou concreta nos últimos anos (por exemplo, a partir do relatório Climate Change 2007, do Painel Intergovernamental de Mudanças Climáticas da ONU). Esse cenário propicia a emergência de uma nova agenda de desenvolvimento. Tal agenda retoma alguns aspectos do antigo desenvolvimentismo, como o protagonismo do Estado na coordenação dos objetivos do desenvolvimento, mas procura também dar conta de desafios percebidos ao longo das últimas décadas, como a necessidade de uma efetiva participação social na definição e na execução das políticas públicas, a expansão das liberdades e das capacidades dos cidadãos em resolver seus problemas e os problemas que envolvem suas sociedades, o resgate de uma relação harmoniosa entre sociedade e natureza, a criação de sociedades mais equitativas dos pontos de vista social e econômico, o estabelecimento de uma convivência mais tolerante e integrada entre os países no âmbito da globalização. Para tanto, é necessário ainda o tratamento do desenvolvimento como um fenômeno complexo (sistêmico, integrado, orgânico...), sem o isolamento entre os seus múltiplos aspectos.

Em outras palavras, é preciso retomar então o papel das estratégias nacionais e do Estado na promoção do desenvolvimento, mas essa retomada precisa estar ciente das modificações ocorridas nas sociedades durante as últimas décadas, onde a divisão do trabalho é cada vez maior, as atividades econômicas são cada vez mais complexas e os interesses sociais, mais heterogêneos. Torna-se indispensável então fazer uso dos mecanismos de democracia deliberativa para o estabelecimento, a legitimação e a execução das políticas de desenvolvimento. Esse esforço enfrenta grandes dificuldades, mas pode gerar grandes resultados e ser mais efetivo do que tentativas unilaterais do Estado, do mercado ou da sociedade civil em promover o desenvolvimento. Para a construção dessa nova lógica, vale considerar as contribuições de Cohen e Evans, que examinam os limites das velhas lógicas de desenvolvimento e procuram avançar em uma proposta inovadora, incorporando os princípios da equidade, da democracia deliberativa e da sustentabilidade, sem abrir mão do aspecto econômico. É preciso encontrar o equilíbrio entre a proposta de Cohen de descentralização da autoridade do Estado na resolução dos problemas locais e a reflexão de Evans sobre um papel ativo do poder público na criação e na expansão das capacidades humanas e na promoção dos interesses socialmente definidos.

A política ambiental brasileira, apesar dos problemas encontrados em sua implementação - como se observou na discussão sobre os conselhos de gestão -, é um exemplo de política que incorpora em sua base conceitual uma lógica de desenvolvimento mais disposta a incorporar a sociedade civil nos processos de tomada de decisão, sem subestimar o papel do Estado na coordenação dos interesses. Como um exemplo dos argumentos de Cohen, observa-se a experiência dos conselhos de gestão, que se apresentam como canais de negociação e decisão das políticas de meio ambiente entre o Estado e a sociedade civil, promovendo, ao mesmo tempo, uma descentralização da gestão dessas políticas. No entanto, a manutenção da participação do Estado nessas arenas de negociação pode ser um meio de se garantir que todos os interesses envolvidos sejam levados em consideração nas tomadas de decisão, como discutido por Evans.

Porém, a implementação desses novos mecanismos de gestão da política tem revelado uma série de desafios a serem enfrentados pelo Estado e pela sociedade na construção desse novo projeto de desenvolvimento. O primeiro diz respeito à dificuldade de se compatibilizar a necessidade de resolução de problemas coletivos (muitas vezes urgentes) com o tempo necessário para a discussão dos interesses envolvidos e a deliberação sobre os mesmos. Outro desafio é garantir que os mecanismos de participação social não sirvam somente para referendar decisões tomadas previamente pelo Estado ou por atores influentes. Uma terceira dificuldade é assegurar a efetiva representatividade dos diversos grupos sociais que possam ser atingidos por determinados projetos de desenvolvimento. Nesse sentido, não se pode perder de vista o fato de que as arenas de negociação social se inserem em esferas de poder simbólico, político e econômico que, muitas vezes, podem privilegiar os interesses de grupos mais influentes. Sendo assim, torna-se claro o papel do Estado em capacitar todos os envolvidos nos processos de negociação, promovendo também a coordenação dos interesses surgidos nessas arenas. Além disso, é preciso que a descentralização do poder do Estado para as arenas deliberativas locais não perca de vista os processos envolvidos nos âmbitos regionais, nacionais e globais.

Por fim, além dos desafios já apontados para a promoção do desenvolvimento, destaca-se o fato de que o 
estabelecimento de uma nova agenda desenvolvimentista é muito mais uma tarefa política do que técnica, demandando um correspondente esforço por parte do Estado e

\section{Referências}

AZEVEDO, A.; SCARDUA, F. Descentralização da gestão florestal: o (des)caso do Mato Grosso. In: ENCONTRO DA ANPPAS, 3., 23-26 maio de 2006. Anais... Brasília, 2006.

BRANDÃO, C. Território e desenvolvimento: as múltiplas escalas entre o local e global. Campinas: Ed. da UNICAMP, 2007.

BRASIL. Lei $n$ 9.985, que regulamenta o art. 225, parágrafo 1, incisos I, II, III, VII da Constituição Federal, institui o Sistema Nacional de Unidades de Conservação - SNUC. Brasília, 2000.

CALEGARE, M.; SILVA JÚNIOR, N. da. Progresso, desenvolvimento sustentável e abordagens diversas de desenvolvimento: uma sucinta revisão de literatura. Desenvolvimento $e$ Meio Ambiente, América do Norte, v. 24, p. 39-76, dez. 2011.

CARVALHO, J. C. A vocação democrática da gestão ambiental brasileira e o papel do poder executivo. In: TRIGUEIRO, A. Meio Ambiente no século XXI. São Paulo: Sextante, 2005.

CMMAD (Comissão Mundial sobre o Meio Ambiente e Desenvolvimento). Nosso futuro comum. 2. ed. Rio de Janeiro: Ed. da FGV, 1991.

COHEN, J. Igualitarismo, internacionalização e cidadania. Revista Brasileira de Ciências Sociais. São Paulo, v. 15, n. 44, p. 161-170, out. 2000.

CONAMA. Resoluções do Conama: resoluções vigentes publicadas entre julho de 1984 e novembro de 2008. 2. ed. Brasília: Conama, 2008.

DIEGUES, A. C. S. O mito moderno da natureza intocada. $3^{\text {a }}$ ed. São Paulo: Hucitec: Núcleo de Apoio à Pesquisa sobre Populações Humanas e Áreas Úmidas Brasileiras, USP, 2001.

DINIZ, E. O pós-Consenso de Washington: globalização, Estado e governabilidade reexaminados. In: DINIZ, Eli (Org.). Globalização, estado e desenvolvimento: dilemas do Brasil no novo milênio. Rio de Janeiro: FGV, 2007. p. 1-336.

Estado, variedades de capitalismo e desenvolvimento em países emergentes. Desenvolvimento em Debate, Rio de Janeiro: EDUFRJ, v. 1, n. 1, p. 7-27, jan.-abr. 2010. da sociedade civil para superar os limites - muitas vezes dogmáticos - que podem ser encontrados.

EVANS, P. In Search of The 21st Century Developmental State. CGPE WORKING PAPER n. 4/08. Brighton: University of Sussex, 2008

FELDMAN, F. Prefácio. In: FURRIELA, Raquel B. Democracia, cidadania e proteção do meio ambiente. São Paulo: Annablume/FAPESP, 2002.

FIANI, R. Cooperação e conflito. Rio de Janeiro: Campus/ Elsevier, 2011.

IRVING, M. A. Áreas protegidas e inclusão social: uma equação possível em políticas públicas de proteção da natureza no Brasil? Sinais Sociais, Rio de Janeiro, v. 4, n. 12, p. 122-147, 2010.

et al. A construção de governança democrática: interpretando a gestão de Parques Nacionais no Brasil. In: IRVING, M. A. (Org.). Áreas protegidas e inclusão social: construindo novos significados. Rio de Janeiro: Fundação Bio-Rio/Núcleo de Produção Editorial Aquarius, 2006.

; MATOS, K. Gestão de Parques Nacionais no Brasil: projetando desafios para a implementação do Plano Nacional Estratégico de Áreas Protegidas. Floresta e Ambiente, Rio de Janeiro, v. 13, n. 2, p.89-96, 2006.

LEFTWICH, Adrian (Org.). Democracy and Development: Theory and Pratice. Cambridge: Polity Press, 1995.

MEDEIROS, R.; IRVING M. A.; GARAY, I. A proteção da natureza no Brasil: evolução e conflitos de um modelo em construção. Revista de Desenvolvimento Econômico, Salvador, ano VI, n. 9, p.83-93, 2004.

PALMA, G. Homogeneous middles vs. heterogeneous tails, and the end of the "Inverted-U": the share of the rich is what it's all about. Cambridge Working Papers in Economics (CWPE) $\mathrm{n}^{\mathrm{o}}$ 1111. Cambridge: 2011. Disponível em: $<\mathrm{http}$ ://www.econ. cam.ac.uk/dae/repec/cam/pdf/cwpe1111.pdf $>$. Acesso em: janeiro de 2012.

PAEHLKE, R.; TORGERSON, D. Managing Leviathan: environmental politics and the administrative state. Toronto: Broadview Press (Ed.). 2005. 
ANTUNES, D.C.; CONTI, B. R. Dilemas de uma Nova Agenda de Desenvolvimento: um olhar sobre...

PNUD (Brasil). Projeto Desenvolvimento Humano no Brasil com a participação do IPEA, FJP e IBGE. Desenvolvimento humano e condições de vida: indicadores brasileiros. Brasília, 1998.

RIBEIRO, J. C. J. A gestão ambiental no Brasil e os Conselhos Estaduais de Meio Ambiente. In: ENCONTRO DA ASSOCIAÇÃO BRASILEIRA DE ENGENHARIA SANITÁRIA E AMBIENTAL, Joinville, setembro de 2003. Joinville: ABES, 2003. p. 1-18.
SACHS, Ignacy. Stratégies de I'écodéveloppement. Paris: Lês Editions Ouvrières, 1980.

SEN, A. Desenvolvimento como liberdade. São Paulo: Companhia das Letras, 2000.

STIGLITZ, Joseph. A globalização e seus malefícios: a promessa não cumprida de benefícios globais. São Paulo: Futura, 2002.

Recebido em março de 2012.

Aceito em maio de 2012.

Publicado em junho de 2012. 